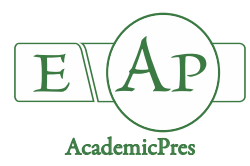

\title{
Assessment of in vitro Antioxidant and Antidiabetic Capacities of Medlar (Mespilus germanica)
}

\author{
Sebnem Selen ISBILIR ${ }^{1 *}$, Sevilay Inal KABALA ${ }^{2}$, Hulya YAGAR $^{1}$ \\ ${ }^{1}$ Trakya University, Science Faculty, 22030, Edirne, \\ Turkey; sebnemselenisbilir@trakya.edu.tr ( ${ }^{*}$ correspondingauthor); hyagar@trakya.edu.tr \\ ${ }^{2}$ Kirklareli University, Vocational School of Health Services, 39060, Kirklareli, Turkey; sevilay.inal@klu.edu.tr
}

\begin{abstract}
The objective of the current study was to evaluate the antioxidant activity and enzyme inhibitory effect of different parts of medlar including fruit, leaf and flower bud by using various in vitro methods, and also determination of total phenolic and flavonoid content in the samples. Ethanol extracts of medlar parts were prepared and their antioxidant activities were determined using 1,1-diphenyl-2-picryl-hydrazil ( $\mathrm{DPPH}^{\bullet}$ ) scavenging and $\beta$-carotene bleaching methods. The leaf extract showed the strongest antioxidant activity. DPPH radical scavenging activity was in the order of BHA $>$ leaf $>$ bud $>$ fruit. This ordering was the same for $\beta$-carotene bleaching activity, tocopherol $>$ leaf $>$ bud $>$ fruit. The highest total phenolic $(60.3 \pm$ $1.69 \mathrm{mg} \mathrm{GAE} \mathrm{g}^{-1}$ extract) and flavonoid $\left(14.77 \pm 1.15 \mathrm{mg} \mathrm{QE} \mathrm{g}^{-1}\right.$ extract) content were determined in leaf extract. For possible antidiabetic effects of extracts, $\alpha$-amylase and $\alpha$-glucosidase inhibitory activities were investigated, the bud extract showed the highest inhibition activities among the all extracts.
\end{abstract}

Keywords: amylase inhibition; DPPH scavenging; glucosidase inhibition; medlar leaf; phenolic content

\section{Introduction}

Mespilus germanica, known as the medlar, is a large shrub or small tree from Rosaceae family. It is a typical climacteric fruit which has gained a value in human consumption and commercial importance in recent years, attracting researchers to study its chemical or nutrient compositions. The most common use of medlar fruits is raw consumption (Glew et al., 2003; Bibalani and Sayadmahaleh, 2012). The medlar is also used in folk medicine, especially by the people of Southeastern Europe, Turkey and Iran, primarily for the treatment of constipation, as a diuretic, or to rid the kidney and bladder of stones (Baytop, 1999; Gharaghani et al., 2016). Medlar also regulates blood circulation, strengthens the nerves and is useful for gastric diseases in the traditional medicine (Bibalani and Sayadmahaleh, 2012). Medlar pulp or syrup is a popular remedy against enteritis (Glew et al., 2003). The medlar leaves are traditionally boiled to use, because local people thought of it to be good for diabetes.

Free radicals are an important risk factor in the pathogenesis of various chronic diseases including asthma, atherosclerosis, aging, cancers, Parkinson's and Alzheimer's diseases, as well as diabetes (Halliwell, 1996; Young and
Woodside, 2001; Valko et al., 2007). Diabetes (DM) is an important metabolic syndrome affecting about 200 million people worldwide. The critical effect of diabetes is postprandial hyperglycaemia and reduction in antioxidant defence mechanism. So, the management of type $2 \mathrm{DM}$ could be achieved both by reducing oxidative stress and by delaying the absorption of glucose through the inhibition of any one of the carbohydrates-hydrolysing enzymes, which are $\alpha$-glucosidase and $\alpha$-amylase. These enzymes are responsible for the breakdown of oligosaccharides and disaccharides into monosaccharide suitable for absorption (Cheng and Fantus, 2005; van de Laar et al., 2005; de Sales et al., 2012).

Natural antioxidants provide the protection of metabolism against the harmful effects of the free radicals and retard process of chronic disorders, as well as the preventing of oxidative deterioration of lipids in foods due to their phenolic contents (Pham et al., 2008; Zamora and Hidalgo, 2016). The phenolic compounds in plants function as free radical scavengers, peroxide decomposing, and enzyme inhibitors. The natural antioxidant source vegetables and fruits present various health benefits for all consumers thanks to their high content of bioactive compounds such as phenolic acids, flavonoids, vitamins and carotenoids (Mattill, 1947; Vaya and Aviram, 2001). 
Therefore, many efforts are performed to search for plant based novel antioxidant compound and enzyme inhibitors to develop natural agents to treat these diseases.

There is little information concerning the antidiabetic activity of parts of medlar, except for its antioxidant activity. Salihoglu et al. (2010), Nabavi et al. (2011) and Ercisli et al. (2012) determined the antioxidant characteristics of medlar plants using different assays. Hence, the in vitro antidiabetic activity, the antioxidant activity and also total phenolic and flavonoid contents of three different parts (flower bud, fruit and leaves) of medlar extracted by ethanol were evaluated in this study.

\section{Materials and Methods}

\section{Preparation of extracts}

The ethanol extracts were prepared from various parts of medlar (Mespilus germanica). These parts of medlar which were grown naturally were collected in 2014 from Kurklareli province, Turkey, and stored at $-20{ }^{\circ} \mathrm{C}$ until use. The fruit, flower bud and leaves of medlar were grounded using a Waring blender. The extraction was performed at a medlar sample to ethanol ratio of $1: 10(\mathrm{w} / \mathrm{v})$ at room temperature for 5 hours in a shaking water bath. After filtration, the extract was evaporated in rotary evaporator to remove ethanol. The extraction yield was calculated as follows:

Yield $(\%)=(\mathrm{g}$ of dry extract $/ \mathrm{g}$ of fresh sample $) \times 100$

Determination of total phenolic and flavonoid contents

Total phenolic content (TPC) in the extracts were determined by using Folin-Ciocalteu reagent (Singleton $e t$ al., 1998). Gallic acid was used as standard, and plotted calibration curve. The equation of this standard graph was determined as $y=0.0005 x+0.0377, R^{2}=0.9983$. The results were expressed as $\mathrm{mg}$ gallic acid equivalent per gram of extract.

Total flavonoid content (TFC) of extracts from different parts of medlar were evaluated with aluminum chloride $\left(\mathrm{AlCl}_{3}\right)$ (Horszwald et al., 2013), using quercetin as standard compound. The content of flavonoid in extracts was expressed as $\mathrm{mg}$ quercetin equivalent using the calibration line equation $\left(y=0.0049 x+0.0615, R^{2}=\right.$ $0.9834)$.

\section{Antioxidant activity methods}

Free radical scavenging activities of the extracts prepared from different parts of medlar were evaluated with 1,1diphenyl-2-picryl-hydrazil ( $\mathrm{DPPH}^{*}$ ) using the Blois method (1958). For determination of total antioxidant activities, a solution of $\beta$-carotene/linoleic acid mixture was prepared, and the total antioxidant activities of the medlar ethanolic extracts were determined in the $\beta$-carotene/linoleate model system using the method described by Miller (1971). $\mathrm{DPPH}^{*}$ scavenging activity and $\beta$-carotene bleaching activity of medlar extracts were calculated as mentioned in the previous studies (Moyo et al., 2010; Orak et al., 2011). The obtained activity values (\%) were expressed as inhibition percentage. The graphs were formed antioxidant activity percentage against different extract concentration, ranging between $50-750 \mu \mathrm{g} \mathrm{mL}^{-1}$ for radical scavenging assay and $250-1000 \mu \mathrm{g} \mathrm{mL}^{-1}$ for $\beta$-carotene bleaching assay.
IC $_{50}$ values (extract concentration providing 50\% inhibition) were determined from the graph plotting inhibition percentage against extract concentrations using GraphPad Prism 5 Demo program.

\section{Alpha-amylase and alpha-glucosidase inhibition assays}

The inhibition activity of medlar ethanol extracts against $\alpha$-amylase was determined according to Apostolidis et al. (2007). After pre-incubation the extract and $\alpha$-amylase (Porcine pancreatic $\alpha$-amylase), starch solution was added to this mixture, and the reaction was stopped by boiling with dinitrosalicylic acid (DNS) color reagent according to assay. Acarbose was used as positive control. The $\alpha$-amylase inhibitory activity was calculated as percentage inhibition.

The $\alpha$-glucosidase (from S. cerevisiae) inhibitory activity was determined as described previously by Bachhawat $e t$ al. (2011). p-nitrophenyl $\alpha$-D-glucopyranoside and acarbose were used as substrate and positive control, respectively. $\alpha$ Glucosidase inhibition was measured spectrophotometrically $(405 \mathrm{~nm})$ in the presence of the extracts or acarbose at $\mathrm{pH} 6.9$.

All experiments were carried out in triplicate $(\mathrm{n}=3)$. The results were expressed as mean values and standard deviation by using Microsoft Excel 2013.

\section{Results and Discussion}

Total phenolic and total flavonoid content of extracts

In present study the leaf, fruit and flower bud of medlar were evaluated for their antioxidant and antidiabetic capacities. Firstly, each part of fresh medlar was extracted with ethanol, and the percentage extraction yields for medlar ethanolic extracts were determined to be $8.50 \%$, $5.49 \%$ and $6.06 \%$ for leaf, flower bud and fruit, respectively. The amount of the chemical compounds in extract depends on polarity of the solvent used in the extraction procedure. Plant kingdom contains numerous chemical compounds such as primary and secondary metabolites. Polyphenols are one of secondary metabolites synthesized in plants including phenolic acids, flavanones, flavones, antocyanidine, isoflavones. The vegetable, herbs and fruit tissues synthesize polyphenols in all parts during their lifespan (El Gharras, 2009). Polyphenol contents, especially flavonoids and phenolic acids, are responsible from showing antioxidant characteristics of plants. Polyphenols are ready to give electrons or hydrogen atoms from their hydroxyl moieties to free radicals due to their conjugated electron systems (Nimse and Pal, 2015). Total phenolic and flavonoid content of all medlar extracts were presented in Table 1. As seen in Table 1, the highest total phenolic (60.3 $\pm 1.69 \mathrm{mg} \mathrm{GAE})$ and flavonoid (14.77 $\pm 1.15 \mathrm{mg} \mathrm{QE})$ content were determined in leaf extract. Similarly, the authors reported higher phenolic content in alcoholic leaf extract of various plant samples including Lantana camara, Teucrium polium L. subsp. polium, Achyranthes aspera (Mahdi-Pour et al., 2012; Stankovic et al., 2012; Kumar and Jat, 2017). Total phenolic content of medlar bud and fruit extracts were $50.3 \pm 0.51$ and $16.5 \pm 3.53 \mathrm{mg} \mathrm{GAE} \mathrm{g}^{-1}$, while their flavonoid contents were $6.54 \pm 0.08$ and $1.99 \pm 0.02$ $\mathrm{mg} \mathrm{QE} \mathrm{g}{ }^{-1}$, respectively. The obtained results showed flower bud extract of medlar contained 3 folds more total phenolic 
386

and flavonoid compounds compared to the fruit extract. Nabavi et al. (2011) also reported that TPC and TFC of methanol extracts obtained from different parts of wild medlar were in the following order: leaf $>$ bark $>$ fruit, which is accordance with our results (leaf $>$ bud $>$ fruit).

Gülcin et al. (2011) reported that TPC and TFC of aqueous extract of medlar fruit were determined to be 25.08 $\mathrm{mg}$ GAE $\mathrm{g}^{-1}$ and $2.39 \mathrm{mg} \mathrm{QE}^{-1}$, respectively. The extraction yield was found to be $4.71 \%$. In another study about medlar, TPC of aqueous extract of leaf was reported to be $55.16 \mu \mathrm{g} \mathrm{GAE} \mathrm{ml}{ }^{-1}$ (Salihoglu et al., 2010). The reported results for both morphological parts of medlar were seen to agree with our results.

\section{Determination of antioxidant activity in extracts}

A single method cannot be utilized to evaluate the antioxidant capacity of vegetable, fruit, plant, because different antioxidant compounds may act through different mechanisms. Therefore, it is suggested that more than one antioxidant tests assayed with different mechanism must be studied when determining the antioxidant capacity of samples (Pellegrini et al., 2003; Apak et al., 2013). The DPPH assay is used widely for the detection of free radical scavenging activity, which is rapid, simple and inexpensive assay. DPPH ${ }^{*}$ scavenging capacity of three morphological parts of medlar was determined at the concentration range of $50-750 \mu \mathrm{g} \mathrm{ml}^{-1}$ for medlar extracts and butylated hydroxyanisole (BHA) as standard compound, which is shown Fig. 1. The leaves and flower bud extracts showed good free radical scavenging activity at the high concentrations. The $\mathrm{DPPH}^{*}$ scavenging activities of leaf extract were determined to be $41.3 \pm 0.7 \%$ and $63.4 \pm 2 \%$ at the concentrations of 100 and $250 \mu \mathrm{g} \mathrm{ml}^{-1}$ respectively, while $\mathrm{DPPH}^{*}$ scavenging activity for $\mathrm{BHA}$ was determined as $82.4 \pm 0.2 \%$ and $85.8 \pm 0.05 \%$ at the same concentrations. The leaf extract showed as high activity as these of BHA at the concentrations of 500 and $750 \mathrm{~g} \mathrm{ml}^{-1}$. The similar $\mathrm{DPPH}^{\bullet}$ scavenging activity profile was observed for bud extract while the activity of bud extract was slightly lower than that of leaf extract at the concentrations of 100 and $250 \mu \mathrm{g} \mathrm{m}^{-1}$.

According to the results of $\mathrm{DPPH}{ }^{*}$ scavenging method, $\mathrm{IC}_{50}$ values were determined to be BHA $\left(28 \mu \mathrm{g} \mathrm{ml}^{-1}\right)$, leaf $\left(157 \mu \mathrm{g} \mathrm{ml}^{-1}\right)$, bud $\left(260 \mu \mathrm{g} \mathrm{ml}^{-1}\right)$ and fruit $\left(695 \mu \mathrm{g} \mathrm{ml}^{-1}\right)$ of medlar from Kirklareli province, Turkey. For eleven medlar genotypes (fruit) from Coruh valley, Turkey, IC 50 values were found to be in range of 22.3- $57.7 \mu \mathrm{g} \mathrm{m}^{-1} \mathrm{FW}$ (Ercisli et al., 2012). IC 50 values obtained from DPPH assay were determined to be $419 \pm 3.2 \mu \mathrm{g} \mathrm{ml}^{-1}$ and $492 \pm 33.1 \mu \mathrm{g} \mathrm{ml}$ for methanol and aqueous extracts of medlar fruit, respectively (Nabavi et al., 2011). The difference between DPPH results obtained from these studies for medlar fruit might be due to the diversity of medlar samples, cultivated area of medlar, and the type of solvent used for the extraction.

Total antioxidant activity of medlar extracts was investigated in linoleic acid emulsion system using $\beta$ carotene bleaching method. The obtained results were given in Fig. 2 by plotting $\beta$-carotene bleaching activity (\%) versus extract concentration.

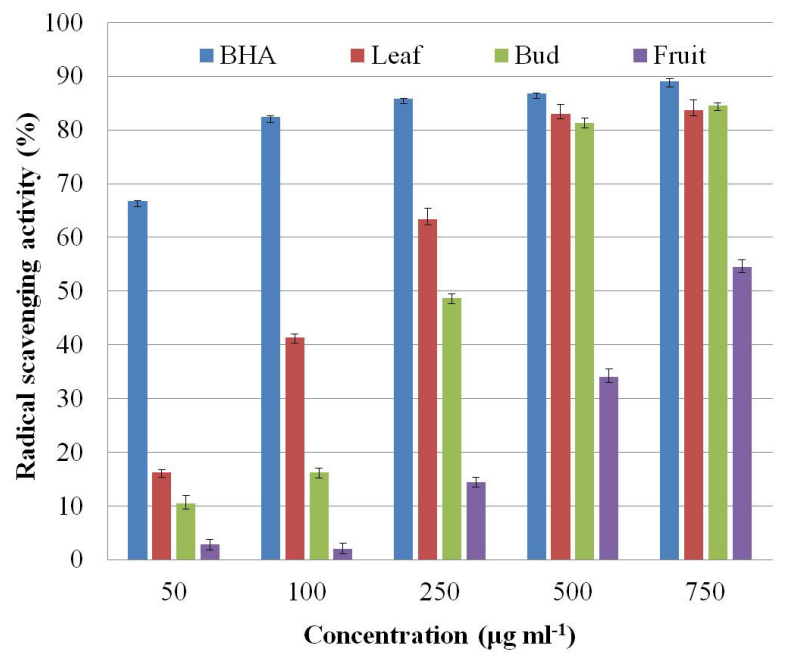

Fig. 1. DPPH radical scavenging activity of medlar parts and BHA

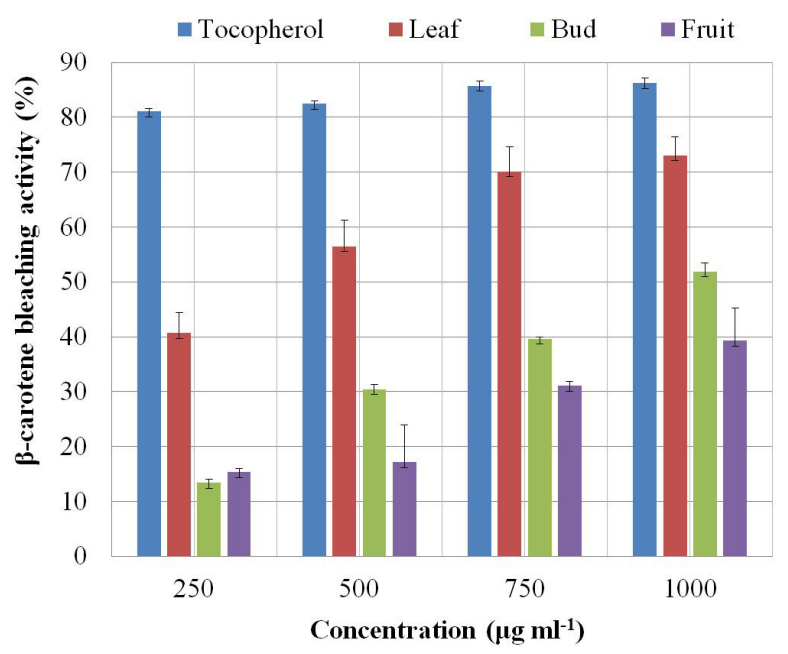

Fig. 2. Total antioxidant activities (\%) of medlar extracts and $\alpha$-tocopherol in $\beta$-carotene/linoleic acid model system

Table 1. Total phenolic content, total flavonoid content and extraction yield of different medlar parts

\begin{tabular}{cccr}
\hline Medlar Part & Extraction yield $(\%)$ & $\begin{array}{c}\text { TPC } \\
(\text { mg GAE/g extract })\end{array}$ & $\begin{array}{c}\text { TFC } \\
(\mathrm{mg} \mathrm{QE} / \mathrm{g} \text { extract })\end{array}$ \\
\hline Leaf & & $60.3 \pm 1.69$ & $14.77 \pm 1.15$ \\
Flower Bud & $5.50 \pm 0.70$ & $50.3 \pm 0,51$ & $6.54 \pm 0.08$ \\
Fruit & $6.06 \pm 0.62$ & $16.5 \pm 3.53$ & $1.99 \pm 0.02$ \\
\hline
\end{tabular}


While the leaf extract $(73.05 \pm 3.2 \%)$ showed close activity to reference compound $(86.23 \pm 0.9 \%)$ at $1000 \mu \mathrm{g}$ $\mathrm{ml}^{-1}$ concentration, the fruit extract has the lowest activity (39.3 $\pm 3.9 \%)$. Nabavi et al. (2011) studied antioxidant activity of medlar methanol and aqueous extracts obtained from leaf, fruit and bark using assays of $\mathrm{DPPH}^{\circ}, \mathrm{NO}, \mathrm{H}_{2} \mathrm{O}_{2}$ scavenging activities and the ferric thiocyanate method. Methanol and aqueous extracts of both bark and leaves showed high antioxidant activity. Ercisli et al. (2012) determined the antioxidant characteristics of eleven medlar genotips using $\beta$-carotene linoleic acid assay, DPPH radical scavenging assay, and total phenolic assay. In $\beta$-carotene linoleic acid assay the antioxidant activity was between $64.6 \%-92.9 \%$ for eleven medlar fruits. In another study, Salihoglu et al. (2010) reported that total antioxidant activities of ethanol, methanol and aqueous leaf extracts of medlar had moderate antioxidant activity by using CUPRAC and the ferric thiocyanate methods.

At the end of $\beta$-carotene bleaching assay, $\mathrm{IC}_{50}$ values were calculated as $4.5 \mathrm{\mu g} \mathrm{ml}^{-1}, 400 \mathrm{~g} \mathrm{ml}^{-1}$ and $960 \mathrm{\mu g} \mathrm{ml}^{-1}$ for tocopherol, leaf and flower bud, respectively. Both of antioxidant activities of medlar extracts assayed in this study decreased in following order: leaf $>$ bud $>$ fruit (Figs. 1 and 2 ). The reason of these ordering may be related to total phenolic and flavonoid contents of extracts. Because total phenolic and flavonoid contents of medlar extracts were also determined to be at the same order (Table 1). It is known that total phenolic content reflects generally the antioxidant capacity of the plant extracts, because the FolinCiocalteu reaction is based on electron-transfer mechanism. According to Salihoglu et al. (2010), in general, free radical scavenging and antioxidant activity capacity of plants are related to their phenolic content. Consequently, the medlar extracts with high phenolic and flavonoid contents were found to have higher antioxidant capacity than the others in this study.

\section{Inhibitor effects of extracts against $\alpha$-glucosidase and $\alpha$ - amylase}

Infusions of medlar leaves are used as a folk medicine for treatment of diabetes (Salihoglu et al., 2010; Arituluk and Ezer, 2012). Not much is known about the antidiabetic potential of medlar plant. Diabetes mellitus is a chronic metabolic disorder and one of the major growing health

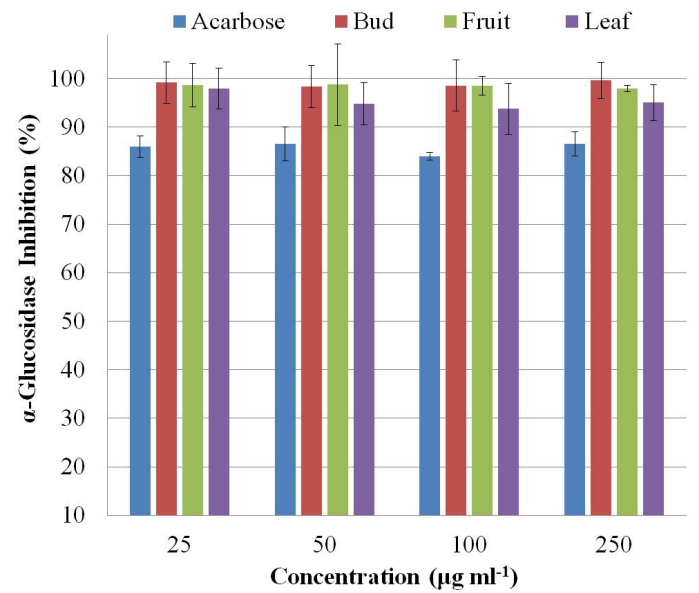

Fig. 3. Alpha-glucosidase inhibitory activity of ethanolic extracts from medlar parts problems. Oral hypoglycemic agents and insulin are the main components of antidiabetic therapy to control postprandial hyperglycemia, which have effect on key enzymes $\alpha$-glucosidase and $\alpha$-amylase (Alhadramy, 2016; Chaudhury et al., 2017). In present study, the leaf, fruit and bud of medlar were evaluated for in vitro inhibition effect on alpha-glucosidase and alpha-amylase enzymes by being compared to acarbose.

All medlar extracts showed inhibitory activity against $S$. cerevisiae $\alpha$-glucosidase while the fruit and bud extracts inhibited porcine pancreatic $\alpha$-amylase (Figs. 3 and 4). The best inhibitory activity against both enzymes was found for medlar bud extract. Many phenolic compounds of natural products have been shown to inhibit the activity of $\alpha$ glucosidase and $\alpha$-amylase (Mayur et al., 2010; Katekhaye and Nagmoti, 2013). The bud extract, which had near so high phenolic content as the leaf extract, showed the highest enzyme inhibition in the both inhibition assays. Interestingly medlar leaf extract which had high phenolic content did not show $\alpha$-amylase inhibitory activity while fruit extract with low phenolic content showed about 35\% of $\alpha$-amylase inhibition at $100 \mu \mathrm{g} \mathrm{ml}^{-1}$ concentration. The high phenolic content determined in the morphological parts of plant with Folin-Ciocalteu method might not indicate its phytochemical diversity. The reason of high inhibitory activity observed in the fruit extract may be the specific compounds existing in the fruit extract, which inhibited $\alpha$-amylase enzyme.

Quantitative amounts of phenolic acids (caffeic acid, ferulic acid, syringic acid, ellagic acid, quercetin, pyrogallol, protocatechuic acid, vanillin, p-coumaric acid, gallic acid) have been reported in medlar fruit (Gülcin et al., 2011; Gruz et al., 2011; Rop et al., 2011). These phenolic acids reported in the medlar fruit may be responsible for the inhibition of $\alpha$-amylase and $\alpha$-glucosidase activities as well as contributing to antioxidant activity. Because numerous studies have reported on the inhibition potential of $\alpha$ amylase and $\alpha$-glucosidase of phenolic acids (Mohamed $e t$ al., 2012; Lordan et al., 2013; Tan et al., 2017; Pradeep and Sreerama, 2018). Consequently, it may be said that the harvest time, the growing area, the morphological part of plant have an important effect on its phytochemical composition and the biological activities such as antioxidant activity and anti-diabetic capacity.

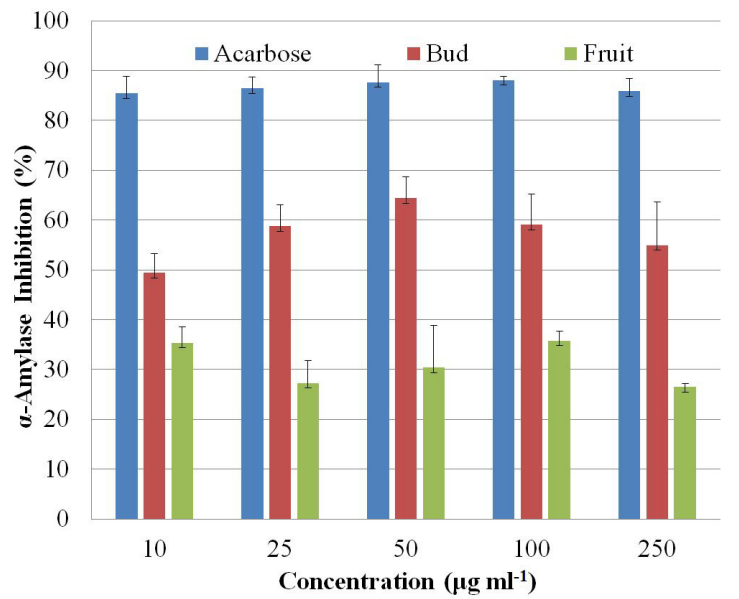

Fig. 4. Alpha-amylase inhibitory activity of ethanolic extracts from medlar fruit and flower bud 
388

\section{Conclusions}

Total phenolic and flavonoid contents, DPPH radical scavenging and $\beta$-carotene bleaching activities of medlar parts were determined to be in order of leaf $>$ flower bud $>$ fruit. The bud and fruit extract of medlar showed inhibition activity against $\alpha$-amylase and $\alpha$-glucosidase, but the leaf extract only showed inhibitory activity on $\alpha$-glucosidase. These results support the traditional use of medlar parts in the management of diabetes, so medlar fruit may be consumed as a dietary component. As a result, the medlar plant with high antioxidant and anti-diabetic capacity may be used both in the prevention of diabetes, which is associated with free radical metabolism, and as a curative in the diabetes treatment. The isolation and identification of the phytochemical compounds which have these pharmacological effects from medlar plant has been expected to make a contribution to design of diabetes medicaments and the pharmacological applications in future.

\section{References}

Alhadramy MS (2016).Diabetes and oral therapies: a review of oral therapies for diabetes mellitus. Journal of Taibah University Medical Sciences 11(4):317-329.

Apak R, Gorinstein S, Bohm V, Schaich KM, Ozyurek M, Guclu K(2013). Methods of measurement and evaluation of natural antioxidant capacity/activity (IUPAC Technical Report). Pure and Applied Chemistry 85(5):957-998.

Apostolidis E, Kwon YI, Shetty K (2007). Inhibitory potential of herb, fruit, and fungal-enriched cheese against key enzymes linked to type 2 diabetes and hypertension. Innovative Food Science and Emerging Technologies 8:46-54.

Arituluk ZC, Ezer N (2012). Halk arasinda diyabete karsi kullanilan bitkiler (Türkiye)-II [The plants used against Diabetes Mellitus in folkmedicine (Turkey)-II]. Hacettepe University - Journal of Pharmacy Faculty 32(2):179-208.

Bachhawat JA, Shihabudeen MS, Thirumurugan K (2011). Screening of fifteen Indian Ayurvedic plants for alpha glucosidase inhibitory activity and enzyme kinetics. International Journal of Pharmacy and Pharmaceutical Sciences 4:267-274.

Baytop T (1999). Turkiye'de bitkiler ile tedavi, gecmiste ve bugun [Curing with Turkish plants in the past and today]. Istanbul: Capa Nobel Medical Books.

Bibalani GH, Sayadmahaleh FM (2012). Medicinal benefits and usage of medlar (Mespilus germanica) in Gilan Province (Roudsar District), Iran. Journal of Medicinal Plants Research 6(7):1155-1159.

Blois MS (1958). Antioxidant determinations by the use of a stable free radical. Nature 26:1199-1200.

Chaudhury A, Duvoor C, Reddy Dendi VS, Kraleti S, Chada A, ... Mirza W (2017). Clinical review of antidiabetic drugs: Implications for type 2 diabetes mellitus management. Frontiers in Endocrinology 8(6).

Cheng AYY, Fantus IG (2005). Oral antihyperglycemic therapy for type 2 diabetes mellitus. Canadian Medical Association Journal 2:213-226.

De Sales PM, De Souza PM, Simeoni LA, Magalhães PDO, Silveira D
(2012). $\alpha$-amylase inhibitors: a review of raw material and isolated compounds from plant source. Journal of Pharmacy and Pharmaceutical Sciences 1:141-183.

El Gharras H (2009). Polyphenols: food sources, properties and applications - A review. International Journal of Food Science \& Technology 44:2512-2518.

Ercisli S, Sengul M, Yildiz H, Sener D, Duralija B, Voca S, Dujmovic Purgar $\mathrm{D}$ (2012). Phytochemical and antioxidant characteristics of medlar fruits (Mespilus germanica L.). Journal of Applied Botany and Food Quality 85:86-90.

Gharaghani A, Solhjoo S, Oraguzie N (2016). A review of genetic resources of pome fruits in Iran. Genetic Resources and Crop Evolution 63:151172.

Glew RH, Ayaz FA, Sanz C, VanderJagt DJ, Huang HS, Chuang LT, Strnad M (2003). Changes in sugars, organic acids and amino acids in medlar (Mespilus germanica L.) during fruit development and maturation. Food Chemistry 83:363-369.

Gruz J, Ayaz FA, Torun H, Strnad M (2011). Phenolic acid content and radical scavenging activity of extracts from medlar (Mespilus germanica L.) fruit at different stages of ripening. Food Chemistry 124:271-277.

Gulcin I, Topal F, Oztürk Sarıkaya SB, Bursal E, Bilsel G, Goren AC (2011). Polyphenol contents and antioxidant properties of medlar (Mespilus germanica L.). Records of Natural Products 5(3):158-174.

Halliwell B (1996). Antioxidants in human health and disease. Annual Review of Nutrition 16:33-50.

Horszwald A, Julien H, Andlauer W (2013). Characterisation of Aronia powders obtained by different drying processes. Food Chemistry 141:2858-2863.

Katekhaye SD, Nagmoti DM (2013). $\alpha$-Glucosidase and $\alpha$-amylase inhibitory activities of Pithecellobium dulce bark and leaves. Phytopharmacology 4(1):123-130.

Kumar V,Jat RK (2017). Antioxidant activity of different extracts of various parts (Leaves, Stem and Root) of Achyranthes aspera. Journal of Pharmacognosy and Phytochemistry 6(6):1862-1865.

Lordan S, Smyth JT, Soler-Vila A, Stanton C, Ross PR (2013). The $\alpha-$ amylase and $\alpha$-glucosidase inhibitory effects of Irish seaweed extracts. Food Chemistry 141:2170-2176.

Mahdi-Pour B, Jothy SL, Latha LY, Chen Y, Sasidharan S (2012). Antioxidant activity of methanol extracts of different parts of Lantana camara. Asian Pacific Journal of Tropical Biomedicine 2(12):960-965.

Mattill HA (1947). Antioxidants. Annual Reviews-Biochemistry 16:177192.

Mayur B, Sandesh S, Shruti S, Sung-Yum S (2010). Antioxidant and $\alpha-$ glucosidase inhibitory properties of Carpesium abrotanoides L. Journal of Medicinal Plants Research 4(15):1547-1553.

Miller HE (1971). A simplified method for the evaluation of antioxidants. Journal of American Oil Chemical Society 48:91-97.

Mohamed EAH, Siddiqui MJA, Ang LF, Sadikun A, Chan SH, Tan SC, Asmawi MZ, Yam MF (2012). Potent $\alpha$-glucosidase and $\alpha$-amylase inhibitory activities of standardized 50\% ethanolic extracts and sinensetin from Orthosiphon stamineus Benthas anti-diabetic mechanism. BMC Complementary and Alternative Medicine 12:176182. 
Moyo M, Ndhlala AR, Finnie JF, Van Staden J (2010). Phenolic composition, antioxidant and acetylcholinesterase inhibitory activities of Sclerocarya birrea and Harpephyllum caffrum (Anacardiaceae) extracts. Food Chemistry 123:69-76.

Nabavi SF, Nabavi SM, Ebrahimzadeh MA, Asgarirad H (2011). The antioxidant activity of wild medlar (Mespilus germanica L.) fruit, stem bark and leaf. African Journal of Biotechnology 10(2):283-289.

Nimse SB, Pal D (2015). Free radicals, natural antioxidants, and their reaction mechanisms. RSC Advances 5:27986-28006.

Oboh G, Agunloye OM, Adefegha SA, Akinyemi AJ, Ademiluyi AO (2015). Caffeic and chlorogenic acids inhibit key enzymes linked to type 2 diabetes (in vitro): A comparative study. Journal of Basic and Clinical Physiology and Pharmacology26(2):165-170.

Orak HH, Yagar H, Isbilir SS, Demirci AS, Gümüs T, Ekinci N (2011). Evaluation of antioxidant and antimicrobial potential of strawberry tree (Arbutus unedo L.) leaf. Food Science and Biotechnology 20(5):12491256.

Pellegrini N, Serafini M, Colombi B, Del Rio D, Salvatore S, Bianchi M, Brighenti $F$ (2003). Total antioxidant capacity of plant foods, beverages and oils consumed in Italy assessed by three different in vitro assays. Nutrient Requirements 133:2812-2819.

Pham-Huy LA, He H, Pham-Huy C (2008). Free radicals, antioxidants in disease and health. International Journal of Biomedical Science 4(2):89 96.

Pradeep MP, Sreerama NY (2018). Phenolic antioxidants of foxtail and little millet cultivars and their inhibitory effects on $\alpha$-amylase and $\alpha$ gucosidase activities. Food Chemistry 247:46-55.

Rop O, Sochor J, Jurikova T, Zitka O, Skutkova, H, Mlcek J, ... Kizek R (2011).Effect of five different stages of ripening on chemical compounds in medlar (Mespilus germanica L.). Molecules 16:74-91.
Salihoglu EM, Akaydin G, Caliskan-Can E, Yardim-Akaydin S (2010). Evaluation of antioxidant activity of various herbal folk evaluation medicine. FABAD Journal of Pharmaceutical Sciences 35:59-67.

Singleton VL, Orthofer R, Lamuela-Raventós RM (1998). Analysis of total phenols and other oxidation substrates and antioxidants by means of Folin-Ciocalteu reagent. Methods in Enzymology 299:152-178.

Stankovic MS, Niciforovic N, Mihailovic V, Topuzovic M, Solujic S(2012). Antioxidant activity, total phenolic content and flavonoid concentrations of different plant parts of Teucrium polium L. subsp. Polium. Acta Societatis Botanicorum Poloniae 81(2):117-122.

Tan Y, Chang SKC, Zhang Y (2017). Comparison of a-amylase, agucosidase and lipase inhibitory activity of the phenolic substances in two black legumes of different genera. Food Chemistry 214:259-268.

Valko M, Leibfritz D, Moncol J, Cronin TD, Mazur M, Telser J (2007). Free radicals and antioxidants in normal physiological functions and human disease. The International Journal of Biochemistry \& Cell Biology 39(1):4484.

Van de Laar FA, Lucassen PL, Akkermans RP, Van de LisdonkEH, Rutten GE, Van Weel C (2005). Alpha-glucosidase inhibitors for type 2 Diabetes mellitus (Cochrane Review). Cochrane Database System Review 18(2):CD003639.

Vaya J, Aviram M (2001). Nutritional antioxidants: Mechanisms of action, analyses of activities and medical applications. Current Medicinal Chemistry-Immunology, Endocrine and Metabolic Agents 1:99-117.

Young IS, Woodside JV (2001). Antioxidants in health and disease. Journal ofClinical Pathology 54:176-186.

Zamora R, Hidalgo FJ (2016). The triple defensive barrier of phenolic compounds against the lipid oxidation-induced damage in food products. Trends in Food Science \& Technology 54:165-174. 